\title{
The development of robust details for sound insulation in new build attached dwellings
}

Received: 3oth September, 2005

Sean Smith BSc, PhD, MIOA

is RC UK Research Fellow and Principal Research Fellow at the Building Performance Centre, School of the Built Environment, Napier University, External Technical Advisor to Robust Details Ltd and joint project manager of the RSD project. He is also Senior Acoustic Consultant with the Robin Mackenzie Partnership.

Dave Baker MRICS, MCIOB, MBEng

is CEO of Robust Details Ltd and former Technical Director of the RSD project and House Builders Federation.

Richard Mackenzie BSc, MIOA, MInstSCE

is Lead Acoustic Consultant with the Robin Mackenzie Partnership and joint project manager of the RSD project.

John B. Wood BSc, DA

is Lecturer in Architectural Technology at the School of the Built Environment, Napier University and designer of the RSD project submission.

Philip Dunbavin MSc, FIOA, MSEE, MIOSH, MInstSCE

is Managing Director and Principal Acoustic Consultant with the PDA Group and Chairman of the RD Inspectors.

David Panter BSc, MIQA

is Operations Manager with Robust Details Ltd.

\begin{abstract}
This paper outlines the background, process and system approach towards the development of robust details (RD) for sound insulation for new build dwellings in England and Wales. Part 1 outlines the initial Robust Standard Details project and its framework, Part 2 describes the structure and operation of the RD scheme for Building Regulation $\mathrm{E}_{1}$ and Part 3 provides feedback on the first operating year of the scheme. In addition, comparisons are made between previous performance levels and constructions used for Part $E$ (1992) relative to the RD approach using recent data feedback from random site inspections and testing.

The results of these early findings suggest that the RD methodology for sound insulation using a coordinated, panindustry approach, in conjunction with criteria direction from government, can lead to an accelerated uptake in improved construction practice and allow government policy performance objectives to be met sooner.
\end{abstract}

Tel: $+44(0) 1314552569$

Fax: +44 (o) 1314552563

E-mail: se.smith@napier.ac.uk

\section{Keywords:}

robust details, sound insulation, housing, noise 


\section{PART 1: THE ROBUST STANDARD DETAILS PROJECT}

\section{Background}

House-building industry given the opportunity to put forward alternative to PCT
On 5th July, 2002, the Minister responsible for the Building Regulations (England and Wales) outlined measures to be included in the new Part E, Resistance to the Passage of Sound (Office of the Deputy Prime Minister (ODPM, 2002). These measures involved the requirement for a minimum proportion of 10 per cent of new build dwellings on each site to be tested for sound insulation (also known as pre-completion testing or PCT). It was also revealed, however, that the house-building industry would be given the opportunity to put forward a possible alternative to PCT called Robust Standard Details (RSD) for new build separating walls and floors in attached houses and apartments. These details for separating walls and floors would require consistently meeting the Building Regulations requirement of Part E, as set out in 2001 in the consultation document for Approved Document E (ADE) (Department of the Environment, Transport and the Regions (DETR), 2000a), and thus would not require routine on-site testing. If the house-building industry was successful in designing and testing such details, these would be presented before the Building Regulations Advisory Committee (BRAC) and released for public consultation prior to a final decision by the Minister.

Following this announcement one of the largest and most intensive projects ever undertaken by the UK house-building industry was initiated by the House Builders Federation, now called the Home Builders Federation. The Building Performance Centre at Napier University was chosen to be the RSD Project Manager.

\section{Project framework and objectives}

The first stages of the project were to provide a boundary framework for submission of potential RSDs and to arrange a suitable structure and process to cater for all sectors of the industry. Five committees were formed, as shown in Figure 1, which included a Steering Group to oversee the whole project, three Working Groups representing the industry sectors of masonry/concrete, timber and steel and a fourth Working Group to assess regulatory issues.

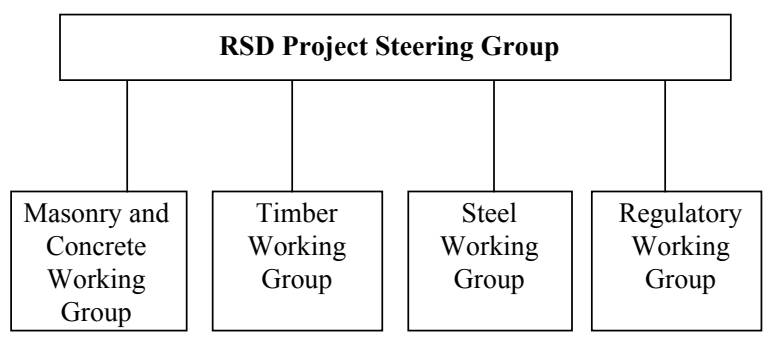

Figure 1: RSD project structure 
The objectives of the RSD were as follows:

- to provide consistent levels of sound insulation performance to meet and exceed the performance standards given in ADE (1992) (ODPM, 1992);

- to have designed in-built robustness to provide suitable reproducibility when built on different sites;

- to reduce the effect of design/material weaknesses that may influence the performance;

- to include a broad range of industry products and practices and provide choice in components and materials;

- to be sufficiently clear in their instructions for correct implementation on site; and

- to be compatible with other building and site regulations.

Due to requirements to submit test results and RSD construction details by the end of May 2003 the timeframe of the project was very short.

\section{Already short timescale of 12 months was effectively reduced to eight months}

Although the announcement was made in July 2002 the project did not officially start until mid-September. Although the timeframe was July 2002 to July 2003, the Working Group meetings could not take place until October 2002. In addition, sites shut down over the new-year period and the project outcomes required publishing and printing in June 2003 for submission in July. This meant that the already short timescale of 12 months was effectively reduced to eight months.

Following the first Steering Group meeting in September 2002 with government representatives to set project framework boundaries, the Working Groups met in October and November to submit potential RSD for separating walls and floors, called Candidate RSD (CRSD). The Working Groups were composed of 119 members including house builders, material/manufacturing organisations and acoustic experts. The Working Groups were charged with looking at submitted constructions and their ability to meet the RSD standards, their robustness and technical compatibility with other current regulations.

The Building Performance Centre (BPC) has a substantial database of on-site sound insulation test results spanning over 30 years of construction, predominantly from tests undertaken in Scotland, involving a diverse spread of separating wall and floor types, systems and materials. This database of constructions was similar to those being built in England and Wales and also included enhanced wall and floor designs. Design and research input from BPC using this database and house builders' previous experience of some constructions allowed the Working Groups to accelerate the identification of certain wall and floor construction formats that would most likely meet the required performance standards.

Each candidate detail was assessed by BPC for:

- reproducibility and repeatability: the ability to be built using a diverse spectrum of on-site workers to meet the required performance standards as set out in Table 1; 
Table I: Comparison of performance criteria for Approved Document E (1992), Approved Document E (2003) and Candidate Robust Details for Part EI

\begin{tabular}{|c|c|c|}
\hline & \multicolumn{2}{|l|}{ Separating walls } \\
\hline & Airborne sound & $\begin{array}{l}\text { Measurement } \\
\text { criteria }\end{array}$ \\
\hline Approved Document E (1992) & $\begin{array}{l}\text { Mean not less than } 53 \mathrm{~dB} \text {, group } \\
\text { individual values not less than } 49 \mathrm{~dB}\end{array}$ & $\mathrm{DnT}, \mathrm{w}$ \\
\hline \multirow{4}{*}{$\begin{array}{l}\text { Consultation Approved } \\
\text { Document E (200I)* } \\
\text { Candidate Robust Standard } \\
\text { Details** }\end{array}$} & Not less than $45 \mathrm{~dB}$ & $\mathrm{DnT}, \mathrm{w}+\mathrm{Ctr}$ \\
\hline & $\begin{array}{l}\text { Mean not less than } 50 \mathrm{~dB} \text {, no individual } \\
\text { value less than } 47 \mathrm{~dB}\end{array}$ & $\mathrm{DnT}, \mathrm{w}+\mathrm{Ctr}$ \\
\hline & \multicolumn{2}{|l|}{ Separating floors } \\
\hline & Airborne sound & $\begin{array}{l}\text { Measurement } \\
\text { criteria }\end{array}$ \\
\hline Approved Document E (1992) & $\begin{array}{l}\text { Mean not less than } 52 \mathrm{~dB} \text {, group } \\
\text { individual value not less than } 48 \mathrm{~dB}\end{array}$ & $\mathrm{DnT}, \mathrm{w}$ \\
\hline \multirow{3}{*}{$\begin{array}{l}\text { Consultation Approved } \\
\text { Document E (200I)* } \\
\text { Candidate Robust Standard } \\
\text { Details** }\end{array}$} & Not less than $45 \mathrm{~dB}$ & $\mathrm{DnT}, \mathrm{w}+\mathrm{Ctr}$ \\
\hline & $\begin{array}{l}\text { Mean not less than } 50 \mathrm{~dB} \text {, no individual } \\
\text { value less than } 47 \mathrm{~dB}\end{array}$ & $\mathrm{DnT}, \mathrm{w}+\mathrm{Ctr}$ \\
\hline & Impact sound & $\begin{array}{l}\text { Measurement } \\
\text { criteria }\end{array}$ \\
\hline Approved Document E (1992) & $\begin{array}{l}\text { Mean not more than } 6 \mathrm{I} \mathrm{dB} \text {, group } \\
\text { individual values not more than } 65 \mathrm{~dB}\end{array}$ & $L^{\prime} n T, w$ \\
\hline $\begin{array}{l}\text { Consultation Approved } \\
\text { Document E (200I)* }\end{array}$ & Not more than $62 \mathrm{~dB}$ & $L^{\prime} n T, w$ \\
\hline $\begin{array}{l}\text { Candidate Robust Standard } \\
\text { Details** }\end{array}$ & $\begin{array}{l}\text { Mean not more than } 57 \mathrm{~dB} \text {, no individual } \\
\text { value more than } 60 \mathrm{~dB}\end{array}$ & $L^{\prime} n T, w$ \\
\hline
\end{tabular}

*Values as now shown in Approved Document E 2003 edition.

*** From July 2004 termed Candidate Robust Detail.

- system approach: relative to the importance of flanking paths, junction details and component variations (eg inner leaf blocks of cavity walls);

- influence of direct and indirect workmanship: eg direct meaning the construction of the separating wall and floor components and indirect meaning works involving other factors such as services and utilities.

Table 1 outlines the performance requirements of ADE 1992 (ODPM, 1992) compared with the consultation document for ADE (2001) (DETR, 2000a) and the CRSD targets for new build separating walls and floors.

\section{Previous separating wall and floor performance}

The task of developing new wall and floor designs required a systematic review of performance levels and construction methods built under the previous Part E requirements. Previous sound insulation testing of dwellings (Sewell and Scholes, 1978) during the 1970s in England and Wales showed failure rates of 55 per cent for walls, 56 per cent for floors (airborne sound) and 63 per cent for floors (impact sound). More recent 


\section{It was estimated that 40 per cent of floors and 25 per cent of walls fail to meet ADE 1992 standards}

\section{Sound testing was a catalyst to improved workmanship and wall and floor designs}

\section{PCT in Scotland took 15 years to reduce failure rates to below 5 per cent}

testing in England and Wales had arisen from complaints and so it was not considered to provide a true reflection of the performance of each wall and floor. In paragraph 10 of the 2001 ADE consultation document (DETR, 2000a), however, the Building Research Establishment estimated that ' $40 \%$ of new separating floors and up to $25 \%$ of new separating walls may fail to meet the ADE 1992 standards'.

In Scotland, the construction details provided in Part $\mathrm{H}$ of the Technical Standards, Resistance to the Transmission of Sound (1990), were very similar to ADE (1992) (England and Wales). Sound testing in Scotland is not compulsory but building control bodies may ask for a sound test of non-Part $\mathrm{H}$ constructions as a method of demonstrating compliance. PCT in Scotland is termed 'post-construction testing'. Following a court case in 1984 (Scottish Special Housing Association v Glasgow District Council [1984], an appeal against a refusal to grant a Completion Certificate), building control officials were also able to request PCT of Part $\mathrm{H}$ constructions as a means of determining whether the workmanship was satisfactory. Only two out of 32 local authorities, Edinburgh and Glasgow, consistently request sound tests in Scotland for both Part $\mathrm{H}$ and non-Part $\mathrm{H}$ separating walls and floors, but these are the two largest cities. Annually, 20,000 dwellings are built in Scotland, four out of every five dwellings are attached and two out of every five dwellings are flats (Communities Scotland, 2002). This provides significant scope for data sampling for the performance of walls and floors not complaint driven.

Test evidence from Scotland showed that sound testing on completion (Craik et al., 1999) was a catalyst to change not only in relation to workmanship but primarily in relation to wall and floor designs (Smith et al., 2001). Key specifiers such as house builders, architects and acoustic consultants learnt through individual experiences that, even with good workmanship, several Scottish wall and floor constructions (similar to some ADE constructions) might have difficulty in achieving the required performance levels.

From the mid-1980s to mid-1990s failure rates in Scotland were between 25 per cent to 50 per cent for some masonry walls, 65 per cent for screed floors and 33 per cent for timber floors (Smith et al., 2001). With changes in design and each specifier learning through costly noncompliance, or asking acoustic consultants to undertake desktop studies of initial designs, the construction designs were improved. This robustness in construction undertaken on an individual site-by-site basis resulted in PCT failure rates falling to below 5 per cent in 2001 in Edinburgh and Glasgow.

These individual site and/or company experiences of noncompliance as a result of PCT in Scotland took approximately 15 years to trickle through to the key specifiers to reduce failure rates to below 5 per cent. In the ADE (2001) consultation document, paragraph 56 stated that the 'proposed changes for new dwellings, particularly the PCT testing regime, are intended to both improve standards and to reduce failure rates to below $5 \%$ over 10 years' (DETR, 2000a).

At the start of the RSD project most separating wall and floor constructions in England and Wales in 2002 were effectively at high 


\section{CRSD target performance is $5 \mathrm{~dB}$ better than ADE requirements}

failure rates for the 1992 Part E regulations. The increase in performance levels for the new Part E (drafted in 2001) even with changes to some ADE guidance structures could potentially lead to a significant failure rate and extra costs and delays. Furthermore, the target performance levels for CRSD to qualify following an average of 30 tests were an average of $5 \mathrm{~dB}$ better than the new ADE requirements.

Examples of improvement changes to separating wall designs by acoustic advisers and specifiers to incorporate robustness measures to comply with the Part $\mathrm{H}$ standards in Scotland when tested on site are shown in Table 2. Similarly, separating floors also had robustness measures introduced, such as the use of batten and cradle floating floor treatments rather than platform floors or screeds, increased thickness or mass of precast slabs and use of resilient ceiling bars for lightweight frame floors. Lessons learnt from the specification changes adopted in Scotland and the guidance for wall ties in the draft ADE (2001) would become very useful to assist the RSD project towards the design of new walls and floors for England and Wales.

\section{Submission process for CRSD}

Initially, submissions of proposals for CRSD could be undertaken by two methods, as shown in Figure 2. The Route 1 method involved submission of measured test data from sites or from full flanking laboratory testing and required submission by early November 2002. The cut-off date of early November for Route 1 was to allow collation of the first phase of CRSD so that the Working Groups could progress forward, house builders could initiate constructions and testing could begin as early as possible.

The Route 2 method allowed those current or new constructions that did not have measured data to enter the CRSD programme. Proposers of constructions through Route 2 were required to submit a maximum of

Table 2: Examples of separating wall construction changes by specifiers in Scotland to improve performance and robustness on site

\begin{tabular}{|c|c|c|}
\hline Core wall construction & Specification change & Acoustic influence of change \\
\hline Solid masonry walls & $\begin{array}{l}\text { Dense } 215 \mathrm{~mm} \text { block only } \\
\text { Blocks laid full width } \\
\text { Single course stretcher bond }\end{array}$ & $\begin{array}{l}\text { Increase mass } \\
\text { Increase stiffness } \\
\text { Increase stiffness }\end{array}$ \\
\hline Inner leafs & Avoidance of risband joints & Reduce flanking sound \\
\hline Inner leafs & Preference for abut and tied & Reduce flanking sound \\
\hline Cavity masonry & $\begin{array}{l}\text { Minimum } 75 \mathrm{~mm} \text { cavities } \\
\text { Set wall tie type }\end{array}$ & $\begin{array}{l}\text { Increase isolation } \\
\text { Reduce bridging effects }\end{array}$ \\
\hline Inner leafs & Set junctions to exterior wall & Reduce bridging effects \\
\hline \multicolumn{2}{|c|}{$\begin{array}{l}\text { NB: masonry walls using dry lining to incorporate sand:cement } \\
\text { render or parge coats and use of dabs } \\
\text { rather than straps }\end{array}$} & $\begin{array}{l}\text { Seal block face, seal open } \\
\text { perpends, increase acoustic } \\
\text { damping and reduce } \\
\text { 'drum effects' }\end{array}$ \\
\hline Lightweight twin frame walls & $\begin{array}{l}\text { Use of wider cavities } \\
\text { Quilt insulation both sides } \\
\text { Set min. cavities for cavity } \\
\text { sheathing boards }\end{array}$ & $\begin{array}{l}\text { Increase isolation } \\
\text { Increase absorption } \\
\text { Reduce resonance effects }\end{array}$ \\
\hline
\end{tabular}




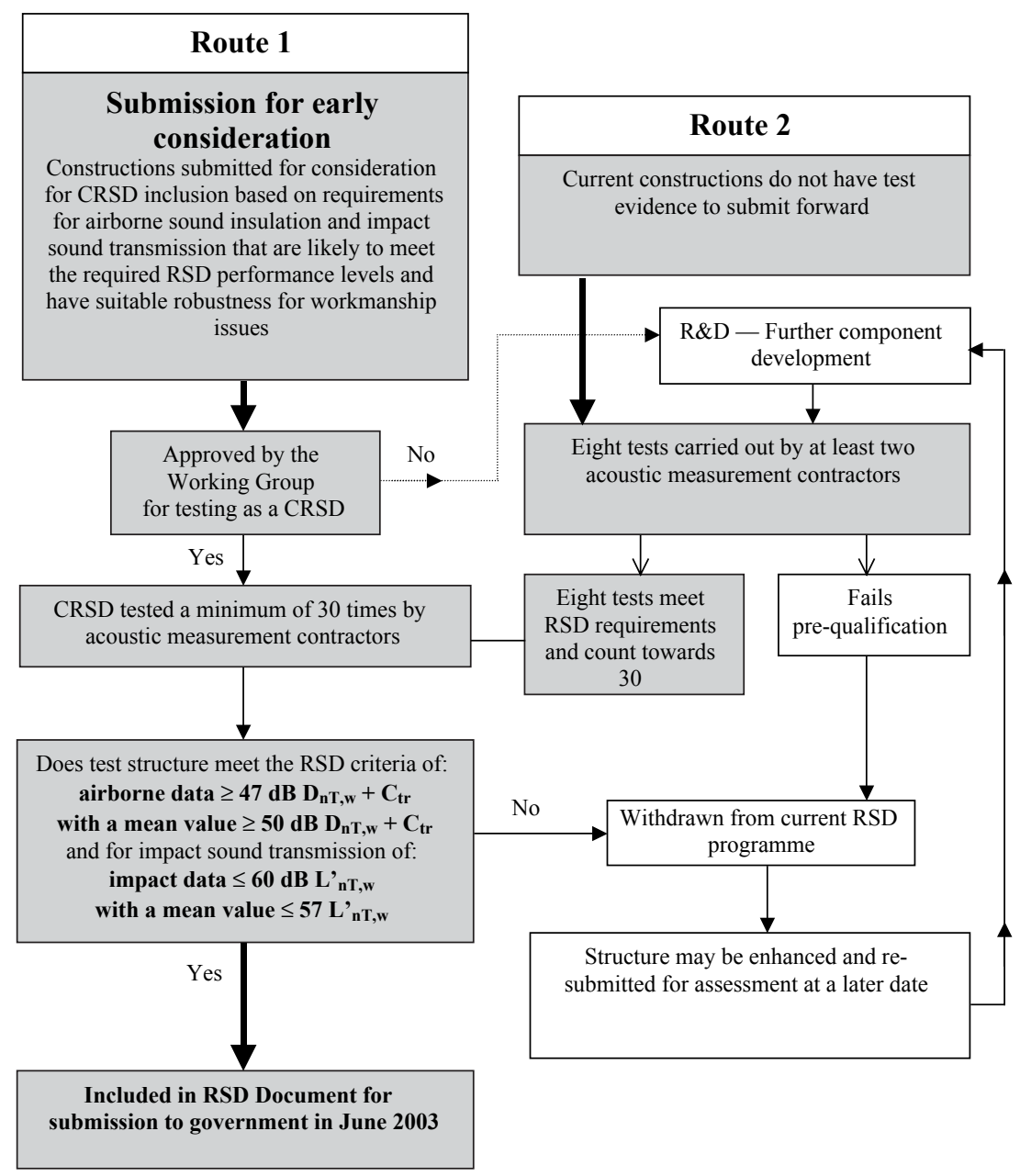

Figure 2: CRSD measurement qualification process

CRSD requires minimum of 30 site tests to qualify eight measurements from PCT tests conducted after November 2002. If these eight test results met the CRSD requirements they could count towards the final group of test results.

\section{Boundary conditions for CRSD testing}

All testing was to be undertaken by an appointed acoustic measurement contractor. The maximum number of tests of any one CRSD from any one site was eight. Each batch of 30 CRSD tests required spreading over a minimum of three different appointed measurement contractors. The 30 test structures required building by two or more house builders or contractors. The project website was the primary method of information transmission with wall and floor design details, committee minutes, updates and news being able to be downloaded.

\section{Acoustic measurement contractors}

In parallel to this, the project managers invited expressions of interest from the acoustic industry to be one of the 12 acoustic measurement 


\section{Increase in complexity of the RSD project management}

RSD process stimulated new areas of R\&D contractors. Decisions relating to the selection were based on test measurement experience, size of staff, geographic location, sets of test equipment, indemnity insurance, calibration certification and ability to meet the project programme. During the first call for 'expressions of interest' over 60 companies applied, ranging from some of the largest consultancies in the UK to one-person operatives. The breadth and scale of the submissions were varied. From this list 12 measurement companies were appointed and a reserve list of test companies was also compiled. Due to the scale of the project several of the reserve testing companies were also subcontracted to undertake testing.

\section{Risk to industry sectors}

The majority of the CRSD involved new separating wall and floor designs. The short timescale of the project required that these new designs had to be incorporated within current new build live sites. This led to an increase in the complexity of the RSD project management, namely finding sites in time and dealing with all the other competing site priorities. Test sites had to be completed within the short 'time window' of the project by certain key dates and at the same time cope with winter construction delays, additional ordering of new materials, ensuring instructions arrived with site personnel in time and finding subcontractors to carry out the works and undertake the tests (PCT) prior to pre-arranged handover dates to clients and occupiers. In addition, all of the aforementioned had to be undertaken in respect of site agents/managers who had never had to deal with PCT before.

Due to the high level of demand for housing at the time of the research project many handover dates had been arranged prior to works even starting at some of the sites. Sites such as traditional housing, with longer build times, had already started and the significant construction changes required to meet the new Part E and RSD criteria resulted in fast tracking of some sites leading to potential increased risk of noncompliance.

\section{Encouraging innovation}

The RSD process also stimulated new areas of research and development into novel designs from material manufacturers for possible future submissions of new CRSD. This then led to the discussion of the potential future possibility of proprietary RSD (ie named or branded products and systems). The attraction of a possible 'living document' (overseen by an RSD Management Board) that could be updated regularly also encouraged pan-industry research and development. Concepts such as a publishable 'mean' and 'range' performance for each RSD might also encourage manufacturing companies to achieve higher performance levels as a marketing strategy in future product development.

\section{Independence of test sites}

To avoid accusations that house builders might try to 'fix' test sites, each CRSD was built by several house builders and in some cases up to nine different ones. Test sites were spread throughout England, Wales and Scotland. Sites in Scotland were also utilised as constructions similar to 
Barrier-free process to knowledge transfer
CRSD were being built on some sites. Each CRSD test site location, house builder and tester was only known to the project managers. In addition, sites were constructed by a wide range of house builders, independent contractors and developers using hundreds of subcontractors. This provided an indication of the variation and spread in sound insulation performance for each CRSD due to these multiple variables.

\section{Pan-industry involvement}

The Working Group discussions brought a tremendous range and quality of technical knowledge together at each monthly meeting. The open distribution of such knowledge and feedback was one of the most positive aspects about the whole RSD process. Committee membership and attendance at meetings was not possible for individual companies and persons could only attend if they were representing an industry association or organisation. This provided a barrier-free process for knowledge transfer of committee discussions and findings and allowed each industry association the ability to keep their members informed.

While there were many examples of 'firsts' that this project achieved for bringing competing industry sectors and companies together, one of the largest new industry associations formed was PASM (Proprietary Acoustic System Manufacturers). These 11 companies manufactured a wide range of acoustic floating floor treatments, wall linings and ceiling systems. As became apparent at the end of the project, the cooperation of these companies through PASM led to the rapid development of a benchmark test programme for a wide range of floating floor treatments, which was integral to the documentation about successful separating floors included within the submission to government.

\section{ISO 717 and $\mathrm{C}_{\mathrm{tr}}$}

The new performance targets of the Part E Building Regulations and use of BS EN ISO 717-1 (1997) spectrum adaptation term $\mathrm{C}_{\text {tr }}$ necessitated careful consideration when choosing all products for wall and floor systems. The new regulatory targets placed significant emphasis on low frequencies $(100-315 \mathrm{~Hz})$ due to the use of $C_{\text {tr }}$. $C_{\text {tr }}$ is normally used for the assessment of the influence on sound insulation on building facades due to low frequency noise sources such as aircraft, trains and heavy goods vehicles (1997). Building facades are normally associated with large external wall areas and noise sources being located in generally 'free field' conditions and are not really representative of separating walls and floor areas and room-to-room testing. Such an emphasis on low frequencies presented a number of issues and variables when attempting to test airborne sound insulation performance between attached dwellings where wall areas were typically less than $12 \mathrm{~m}^{2}$ and room volumes varied from $15-40 \mathrm{~m}^{3}$.

Although rooms of less than $25 \mathrm{~m}^{3}$ are suggested as being unsuitable for PCT (DETR, 2000a), occupants are still exposed to noise from adjoining dwellings. In addition, the increased higher density designs to meet PPG3 (DETR, 2000b) planning requirements meant that many rooms tested for the project would be less than $25 \mathrm{~m}^{3}$. 
If research project sites used checklists this might lead to a bias in expected performance

\section{QA procedures for the future of RSD}

The regulatory group discussed at length the importance of how the RSD could be checked by site managers. While the RSD designs should achieve the set insulation performance requirements and the robustness of the designs should cater for most workmanship variances, the supervision of on-site personnel was still important. Issues such as the increasing use of subcontractors, reduction in skilled labour and the pressures to reduce build time on sites might result in less supervision and increase the risk of noncompliance. In addition, indicating to the site management and personnel the importance of key construction factors would assist in the knowledge transfer of 'how' and 'why'. As a result, each RSD would have details showing the key junctions with other building elements (eg external walls) and a checklist that the site agent/manager would be required to sign off.

During the project a suggestion was put forward that all research project sites should use the checklists. However, it was decided that if the research project sites used checklists it might lead to a bias in the expected performance of the walls or floors and would not take account of the risk of future sites that did not use a checklist, if RSD were adopted. Thus it was decided that no project sites would be given checklists or receive any additional advice or support other than the instructions to build a set wall or floor.

\section{Size and scale of the RSD project}

The research project led to some interesting statistics in terms of its size and scale. Over 58 house builders participated providing over 160 live sites. Access was required to over 1,300 dwellings to test the various CRSD. Over 350 companies were represented through the committees and 15 acoustic consultancy subcontractors were appointed for testing the new walls and floors. Figure 3 illustrates the spread of test site locations of some of the 160 project test sites.

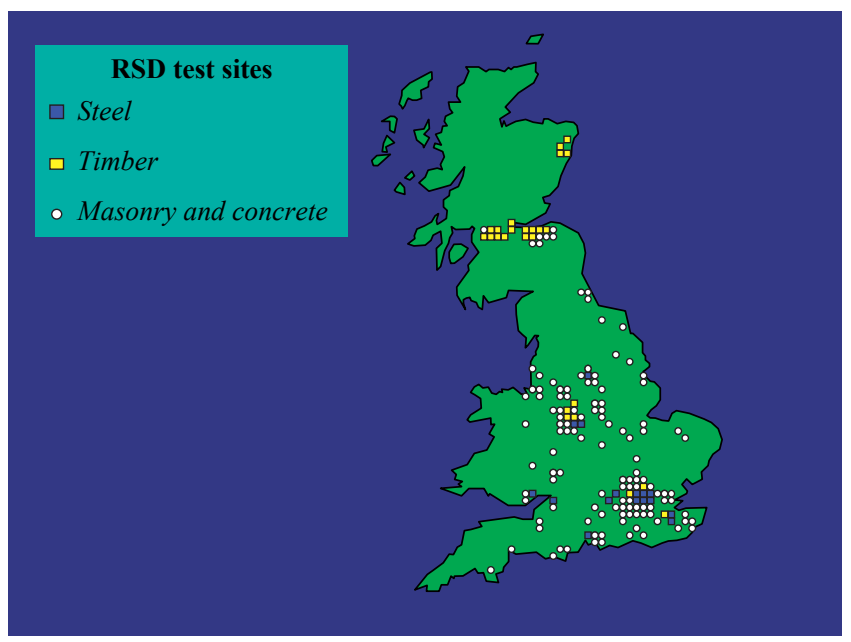

Figure 3: Locations of some of the I60 RSD project test sites across England, Wales and Scotland divided into their core structural constructions 
In January 2004 the government announced that the RSD process would be acceptable
In the first few months of the project the project website received 2,800 regular visitors and over 10,000 documents, including wall and floor designs, were downloaded.

During the project several CRSD were withdrawn due to not meeting the performance requirements. The final documentation was submitted to government on time for the July 2003 deadline, including all design details for the first 13 fully tested RSD. Each RSD required a minimum of six pages of designs including checklists. Given that the last site to be tested was in May the full documentation required designing and fully drafting in only five weeks.

The performance level of the wall and floor robust details (RD) submitted was on average $10 \mathrm{~dB}$ better than the previous regulatory mean standards for sound insulation. This would lead to a significant increase in the subjective level of sound insulation experienced by dwelling occupants.

\section{From RSD to RD}

In August 2003 the RSD proposal was issued for public consultation to assess whether this could be used as a means of compliance with Part E1 of the Building Regulations (ODPM, 2003a). In January 2004 the government announced that the RSD proposal would be acceptable as an alternative compliance route for new build dwellings instead of PCT, starting from 1st July, 2004. The government was concerned, however, that there should still be some form of monitoring and inspection to ensure the construction details and performance levels were being followed. As a result, Robust Standard Details was changed in name to Robust Details for Part E and operated by a non profit distribution company called Robust Details Ltd.

\section{PART 2: RD AS COMPLIANCE FOR BUILDING REGULATIONS}

\section{RD for Part E}

Robust Details Ltd is a non profit distributing company limited by guarantee which works in accordance with a Memorandum of Understanding between Robust Details Ltd and the ODPM. The role of Robust Details Ltd is to:

- approve new RD as a method of satisfying Building Regulations;

- manage the use of RD in the house-building industry by enabling builders or their representatives to use them in new, attached homes;

- monitor and inspect the use of RD by spot-check inspection and testing of a sample of RD separating walls and floors. Currently, Robust Details Ltd aims to visually inspect 1 per cent and test 2 per cent of all RD plot registrations.

Given that the PCT route would require a minimum of 10 per cent of all dwellings on each site to be tested and then have further 10 per cent subgroupings for variations on each site, such as flats, attached houses, changes in flanking conditions or room sizes, the RD route is removing a
RD route is removing a significant barrier to construction delays 
significant barrier to construction delays and site shut downs while PCT is undertaken.

The work of Robust Details Ltd is managed by a Management Board and overseen by the ODPM. The Board comprises representatives of:

- Home Builders Federation

- ODPM Building Regulations Division (observer)

- Private sector building control: NHBC Building Control Services

- Public sector building control regulator: LABC Services

- RICS Building Control Forum

- Warranty provider: NHBC

- Association of Noise Consultants

- Building Performance Centre, Napier University

- Construction Products Association

- Consumer representative

- Supplier representative.

The primary issue of providing information to RD users is dealt with via the RD handbook (Robust Details Ltd, 2004, 2005a, 2005b), which contains all the wall and floor designs with additional supporting guidance and information. All supporting documentation and application forms and procedures are provided via the website (www.robustdetails.com).

\section{Organisation and procedures}

There are several functions that provide the structure as to how the process of RD for Part E operates. Figure 4 provides a summary of the organisation and some of the key elements in the building appraisal of RD for sound insulation.

\section{Performance and monitoring committee}

The role of this committee is to collate and monitor feedback from the $27 \mathrm{RD}$ inspectors who cover various regions across the whole of England

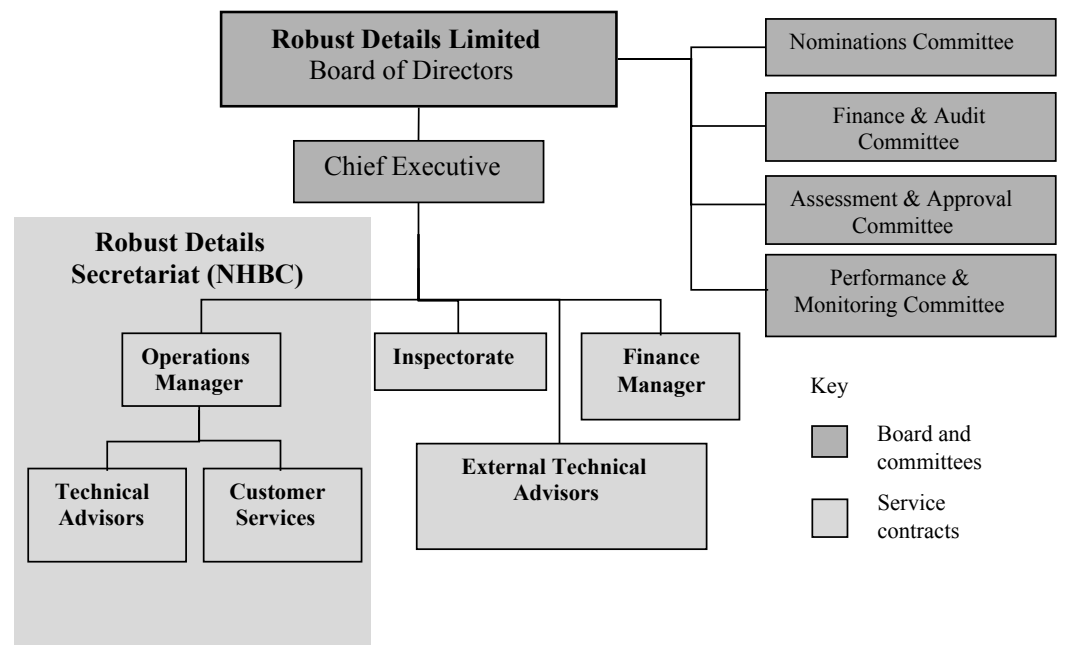

Figure 4: Summary of the RDL organisation 
Over 60 per cent of RD plot registration fee funds RD inspection and performance monitoring and Wales. Site inspection feedback and random sound test data recorded via testing samples of completed plots allows the performance and construction process to be monitored and tracked. The RD inspectors are not a replacement for normal building control procedures. Over 60 per cent of the plot registration fee funds the costs of running the RD inspectors and performance and monitoring. Further information on the financial operations and costs can be found in the 2005 annual report (Robust Details Ltd, 2005c).

\section{Approvals and assessment committee}

With the ongoing research and development by construction product manufacturers, house builders using new forms of system build, developments in modern methods of construction and the implications to constructions of changes in other Building Regulations it is important that there is the ability to bring forward new candidate RD. Figure 5 outlines the process by which new candidate RD can be brought forward for assessment and review involving a three-stage process - A, B and C which is similar to the Route 2 process that was developed during the RSD project (see Figure 2). Figure 6 illustrates the complete process of an RD from submission as a new candidate wall or floor to performance monitoring on site of the constructed RD.

\begin{tabular}{|c|c|c|}
\hline $\begin{array}{c}\text { STAGE A } \\
8 \text { test sets }+ \\
\text { robustness } \\
\text { assessment }\end{array}$ & $\begin{array}{c}\text { STAGE B } \\
22 * \text { test sets }+ \\
\text { robustness } \\
\text { assessment }\end{array}$ & $\begin{array}{c}\text { STAGE C } \\
\text { Publication in } \\
\text { Handbook }\end{array}$ \\
\hline
\end{tabular}

*A reduced number of stage B test sets would be required for new flanking conditions to existing robust details, and might also be acceptable in the case of some new components of existing robust details

Figure 5: Three-stage process for Candidate Robust Detail (CRD) assessment and design into RD handbook

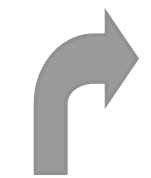

(3) Publication in handbook

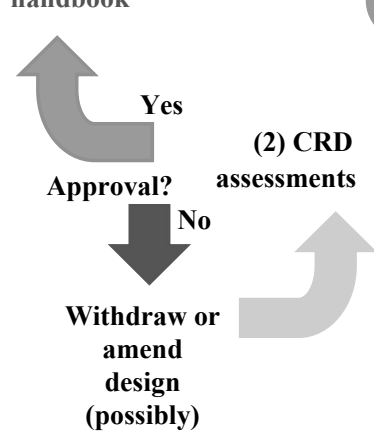

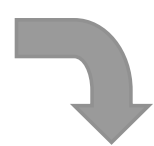

(5) Performance monitoring
Figure 6: Key processes for new RD from submission to on-site performance monitoring 


\section{Technical support}

The wide spectrum of dwelling types, designs, construction features, relationships to other Building Regulations and general technical enquiries requires a fully operational technical support desk to respond and advise on queries from design offices, building control and sites. The availability of this technical support via the technical advisors and technical consultants is an important element in dealing with such queries and assisting in reducing possible delays before and during construction.

\section{Dwelling plot registration process}

Applicants wishing to use the RD route towards Part E1 compliance are required to register each plot with Robust Details Ltd by paying a fee of $£ 30$ per plot. The fee is per plot and thus more than one RD may be used per plot. Once plots are registered, the applicants are provided with registration documentation, which is accepted by building control bodies as evidence of the entitlement to use RD instead of pre-completion sound testing.

Robust Details Ltd provides a choice of possible construction solutions that have been proven from 30 field tests to exceed the standards of Part E and meet the additional RD 'robustness' criteria. Site checklists and compliance certificates are also supplied with the registration documentation. Site managers are asked to use the checklist to help to ensure that the building work is carried out in accordance with the relevant $\mathrm{RD}$. Once the separating wall(s) and/or floor(s) in each home are completed, the site manager is required to fill in the compliance certificate for the plot and make it and the completed checklist available to the building control body and warranty provider.

The role of building control is crucial to the maintenance of RD as an alternative means of satisfying Building Regulation E1 and ADE (2003) (ODPM, 2003b). The Part E RD scheme depends upon building control bodies requiring builders to undertake pre-completion sound testing in new attached dwellings in England and Wales, unless the dwellings are registered with Robust Details Ltd and built in accordance with the relevant RD specifications. The Building Regulations impose these requirements on the person carrying out the work.

Each time an applicant (usually the house builder, developer or their designer) registers plots to be built using RD, a purchase statement is sent to the applicant which they then pass on to the building control body. Evidence, in the form of the purchase statement, is required to be given to the building control body generally no later than at the start of building work.

The purchase statement lists all of the individual registered plots and a

A unique registration number is assigned to each plot unique registration number is assigned to each plot. The RD handbook, which includes the RD specification sheets and site checklists, is an essential tool that helps both the house builder and building control bodies to ensure that separating walls and floors are built properly. 
In summary, the RD process aims to ensure that the following is achieved without imposing an unreasonable burden on the building control body:

- the builder is only permitted to use RD instead of pre-completion sound testing if the plots concerned have been registered in advance with Robust Details Ltd;

- the builder constructs separating walls and floors strictly in accordance with the relevant specification sheets and checklists.

If the procedure outlined above is not observed in full then the dwellings must be subject to pre-completion sound testing.

Each RD wall and floor design has an individual identification code which allows the construction of each RD to be tracked and easily identified. The individual coding of an RD adopts the following sequence:

- all RD codes start with (E) for Part E of the Building Regulations

- followed by (W) or (F) for wall or floor;

- followed by the core structural build, ie (M) for masonry, $(\mathrm{T})$ for timber, (S) for steel or (C) for concrete;

- followed by the individual number in order of appearance within the RD handbook.

\section{PART 3: FIRST YEAR OF OPERATION}

\section{Use of RD for sound insulation}

The adoption of RD in the first year as a means towards compliance with Part E1 of the Building Regulations has been well beyond all forecasts and expectations. In the first year of its operation over 100,000 new build dwellings have been registered using the enhanced wall and floor designs.

The average number of RD being used per plot is 1.4, perhaps due to the increasing development of sites incorporating flats and apartments. All regions of England and Wales are adopting the designs and the ability to record the location of where wall and floor designs are being built for the first time has provided a detailed source of national, regional and local specific construction and design information.

Over 8,000 RD handbooks are in use and since the first edition prior to July 2004, when RD came into effect, a second edition was published in January 2005 with an update to the second edition in September 2005, both incorporating new RD designs.

To address the required expansion the number of RD inspectors has increased from 18 to 27 and the technical support service has expanded.

\section{Early monitoring and feedback}

It was suggested in the consultation document (paragraph 40) that the monitoring would not start until after a reasonable number of new homes had been built, which was likely to be about one year after the system was introduced. The monitoring processes and systems were started earlier 


\section{6 per cent of site performance tests achieved the RD standard}

than predicted and, although it is too early to draw any specific conclusions, this has provided some interesting feedback. In the first early period, over 1,000 plot visual inspections and over 350 random sample sound tests on site have been undertaken via the performance and monitoring and RD inspectors. No same plots are inspected and tested as potentially this would present a statistical bias and reduce the ability to monitor the RD performance accurately.

Initial feedback from the visual inspections of the RD on sites has revealed that 91 per cent of the inspections required no corrective action and 96 per cent of the site performance test results achieved the RD assessment performance standard. Where significant deviations from the $\mathrm{RD}$ scheme were found these have been passed to the building control body for action.

Initial feedback from the random sample sound tests has found that the average performance of the $\mathrm{RD}$ is $+2 \mathrm{~dB}$ better than was found during the RSD project.

\section{DISCUSSION}

The scheme is still in its early stages, further maturity is necessary and larger sample sizes will be required prior to drawing any specific conclusions. As new Building Regulations are brought in, new RD are developed and an increasing number of site personnel transfer from older Part E construction sites to new RD construction sites there is still a significant quantity of knowledge transfer required.

Early indications from the performance and monitoring process suggest that visual inspections may be of greater use in the long term to catch individual plots and sites that may deviate significantly from the RD scheme. Thus the current weighting requirement to be undertaken by Robust Details Ltd of more tests than inspections may not present the optimum methodology of approach in the future. But until at least twothree years of monitoring have been undertaken and a statistically significant data sample is available it is still too early to review this weighting.

Although the checklists were not part of the RSD project and were not included in the regulatory requirement stipulated in the government's summary of the scheme, their use by site managers has seen a significant increase. This increase is due to the building control bodies and RD inspectors requesting to see these during site inspections. Such an approach will have a positive impact on the construction and performance of RD and in the process of knowledge transfer to site managers and operatives.

The initial feedback in the first year from RD inspections suggests high compliance rates for both build and performance, providing encouragement when compared with previous failure rates of older Part E-type constructions of between 25 per cent and 65 per cent.

In Scotland the trickle process of knowledge transfer to key specifiers took approximately 15 years to reduce the failure rates to below 5 per cent via building control requested PCT. It was estimated that it would take ten years using PCT in England and Wales to reduce failure 
rates to below 5 per cent. The results of these early findings suggest that the RD methodology for sound insulation using a coordinated, pan-industry approach, in conjunction with criteria direction from government, can lead to an accelerated uptake in improved construction practice and allow government policy performance objectives to be met sooner.

\section{Acknowledgments}

The authors are grateful for the support throughout the RSD project of the various industry committee members and house builders who provided the research test sites. The authors also wish to thank Professor Robin Mackenzie of the Building Performance Centre for technical advice and support throughout the RSD project. In addition, the authors wish to acknowledge the Robust Details Ltd staff and, in particular, Simon Bloodworth and Phil Rogers. Finally, the authors gratefully acknowledge the technical feedback from house builders, developers, architects and contractors regarding the RD scheme.

\section{References}

British Standards Institution (1990) 'Technical Standards Part H - Resistance to the transmission of sound', The Building Standards (Scotland) Regulations. HMSO, London, UK.

British Standards Institution (1997) BS EN ISO 717-1: 1997, Acoustics - Rating of Sound Insulation in Buildings and of Building Elements - Part 1. Airborne Sound Insulation.

Communities Scotland (2002) The Scottish House Condition Survey, Communities Scotland, Edinburgh, UK.

Craik, R.J.M., McPherson, A. and Somerville, A.W.M. (1999) 'The relationship between post construction testing and sound insulation performance. Technical note', Applied Acoustics, 57 , 79-87.

DETR (2000a) Consultation Documents: Proposals for Amending Part E - Resistance to the Passage of Sound. The Building Regulations, DETR, London, UK, January.

DETR (2000b) Planning Policy Guidance Note No. 3: Housing, DETR, London, UK, March.

ODPM (1992) Approved Document E (1991) Resistance to the Passage of Sound. The Building Regulations, ODPM, London, UK.

ODPM (2002) Government moves to drown out noisy neighbours. News release 2002/027, ODPM, London, UK, July.

ODPM (2003a) Consultation Documents: Amendment of the Building Regulations to Allow Robust Standard Details to be Used as an Alternative to Pre-completion Testing. The Building Regulations, ODPM, London, UK, August.

ODPM (2003b) Approved Document E, Resistance to the Passage of Sound. The Building Regulations, ODPM, London, UK.

Robust Details Ltd (2004) 'Resistance to the passage of sound', Robust Details Part E Handbook, 1st edn, Robust Details Ltd, Milton Keynes, UK, May.

Robust Details Ltd (2005a) 'Resistance to the passage of sound', Robust Details Part E Handbook, 2nd edn, Robust Details Ltd, Milton Keynes, UK, January.

Robust Details Ltd (2005b) 'Resistance to the passage of sound', Robust Details Part E Handbook, 2nd edn, Robust Details Ltd, Milton Keynes, UK, Update edition and September.

Robust Details Ltd (2005c) Annual Report, Robust Details Ltd, Milton Keynes, UK.

Sewell, E.C. and Scholes, W.E. (1978) Sound Insulation Performance Between Dwellings Built in the Early 1970s, Building Research Establishment, Garston, Watford, UK, CP 20/78.

Smith, R.S., Mackenzie, R.K., Mackenzie, R.G. and Waters-Fuller, T. (2001) A Review of Sound Insulation in Scottish Domestic Construction, Buildings Division, Scottish Executive, Edinburgh, UK. 